\title{
0666 SOCIAL SYSTEM ANALYSIS OF CHILD ABUSE PREVENTION NETWORK IN LOCAL COMMUNITIES OF JAPAN
}

I Kakefuda*, K Kitamura, Y Nishida, T Yamanaka, Y Motomura Correspondence: Digital Human Research Center, National Institute of Advanced Industrial Science and Technology 2-3-26 Aomi, Koutou-ku Tokyo 1350064, Japan

\subsection{6/ip.2010.029215.666}

Recently child abuse has been recognised as a serious child health and welfare issue in Japan. Efforts to protect children from violence and neglect are hampered by lack of coordination among institutions and agencies, sometimes resulting in the worst consequences. The study aimed to understand current strengths and weakness of child abuse prevention networks, taking two local communities in Japan as examples. Using the perspectives of stakeholder analysis and community readiness analysis, we analysed how stakeholders in networks worked together and what problems in the networks prevented them from reaching their goal. Two local communities were selected because both communities had distinctive individuals (stakeholders) in institutions and agencies working for child protection, who were willing to participate in the study. Ten stakeholders participated from police agencies, child protection agencies, maternal and child health agencies, hospitals and nursery schools. Interviewers used a semi-structured questionnaire and asked for opinions about the quality of coordination in the networks, resource allocation and use by each institution and agency, and concerns about coordination. Interview contents were qualitatively evaluated and concordances and discrepancies in opinions among stakeholder individuals were assessed to understand the whole picture of child abuse prevention network coordination in the two communities. Results show that agencies and institutions sometimes have goals different than protecting children, for example, reluctance to report potential cases to police due to worries about making false accusations or retaliation from families. The method is helpful to understand and improve the quality of child abuse prevention networks. 